\title{
Business Leadership Effectiveness: Kazakhstan Approach
}

\author{
Keun Jung Lee \\ Bang College Business, KIMEP University \\ Alma Alpeissova \\ Bang College Business, KIMEP University \\ Ayaulym Akisheva \\ Bang College Business, KIMEP University
}

\begin{abstract}
This is interest in the research of the leadership in business sector in Kazakhstan and in the responder's attitude and preferences as to the leadership styles business executives employ, taking into consideration the developing stage of business activities in Kazakhstan. This study focus on the analysis of the leadership styles with employee performance and the survey research method was used. The questions were arranged according to six point Likert scale. Kazakhstan employees prefer such leadership styles as transformational, father, democratic, transactional and in some cases authoritative leadership styles. Kazakhstani employees prefer to be heard and supported, prefer to be a part of the organizational endeavors, contribute and add value to organizational development. Furthermore, as the study shows, Kazakhstani employees reject the coercive leadership style. They do not want to be a part of an organization, where force and ignorance of people's values are considered to be as a normal attitudes. Nowadays within the development processes in Kazakhstan, leadership has big influence on organizational performance and company's effectiveness.
\end{abstract}

Keywords: Leadership style, Transformational, Democratic, Father Leadership, Authoritative, Coercive, Transactional Leadership, Kazakhstan

\section{INTRODUCTION}

In the evolving sphere of business activities. Leadership has taken its place as an integral part of success and competitiveness of organization. The importance and effectiveness of leadership cannot be underestimated: leaders help nations through time perils, they make business organizations successful and lead them towards fulfillment of their missions and goals [9]. Leadership for the future of any organization should be considered as one of the top priorities, as it is driving force for operational growth and sustainability. In his book "Leadership: How to lead, How to live" D. Quinn Mills defined the importance of leadership as such that without it organizations will not be able to make use of good decisions, they will "move slowly" and "stagnate" [9]. Leadership is seen as a catalyzer for change and implementation of decisions and plans. Furthermore, true leaders, by exemplifying their leadership, continue to other people's development and productiveness [9]. It can thus be stated with no doubt that behind great success and significance of any organization there is a leader, who has an ability and zeal to move towards the set goals and objectives.

The commonly described leadership styles are: coercive leadership style, authoritative leadership style, affiliated leadership style, democratic leadership style, pacesetting leadership style, coaching leadership style [5], and transactional and transformational leadership styles [1]. According to scientists, true leaders use various styles, while directing their followers towards achievement of their goals and objectives and each of these styles has its positive or negative effects [4]. Accordingly, while development of a person as a leader involves true 
commitment to personal development and consistent work on himself/herself, the leadership styles used towards motivating leaders' followers is no exception. Each of these styles can be learned and practiced to reap the best results both for leaders and also their followers and this require attention to be drawn towards the most effective and positive of them.

Furthermore, outstanding results can be achieved by means of sound leadership and also sound implementation of the visions and set goals, which in their turn depend on the employees of organizations or strictly speaking on the followers of the leaders of organizations. Accordingly, the importance of the evaluation of the impact, effectiveness of leadership styles on employees' performance cannot be overestimated together with the identification of the most influential and positive ones.

This paper will test the existence of the relationship between leadership styles and employee performance to understanding of business leadership in Kazakhstan.

\section{LITERATURE REVIEW}

The concept of leadership and development of leadership capabilities is rather new concept for young Kazakhstan. Nevertheless, there are numerous researches on leadership within political sphere in Kazakhstan. One of those researches suggests that there is an impact of leadership and its effectiveness on the perceptions, on attitudes of followers and on country's domestic as well as international image [6]. Unlike numerous researches of leadership within political framework in Kazakhstan, the leadership concept within business framework is not much researched. Thus, it is important to define leadership effectiveness and to see how leadership affects employee performance within the business framework. Before moving on with the main topic of the research studying the impact on employee and operational performance in companies in Kazakhstan, the leadership and its types that currently are known in the general academic and business spheres are to be defined.

The development of leadership theory entails the gradual investigation of different types of leadership, that correspond to and illustrative of particular period. With the notion of coercive leadership one might think that this type of leadership is mostly illustrative of ancient times when things got done by use of force and it can be put on the lowest level of leadership development theory. There are 8 leadership styles that would be described in this research and then analyzed.

Coercive leadership is based on the notion of "immediate compliance" where orders of the leader shall be complied without any questioning and comments [5]. This particular leadership style usually produces negative results as it disincentives initiative and takes back the employees' sense of ownership of the work they perform [5]. While this type of leadership, which is akin to strong-willed type of leadership described above, it generally inadvisable it can produce good results in the times of crisis, turnarounds and problems with employees [5]. This leadership style is thus should not be completely overlooked, but should be used rarely, during the times of high need and crisis. The common characteristics of coercive leaders is that they have complete power of their people, thereby, team members have little opportunity to make suggestions even if these would be in the best interest of organization [10]. In this type of leadership high emphasis is placed on performance with low emphasis being placed on people, as the underlying philosophy is that people tend to be lazy, undependable, dislike work, resist responsibility, work primarily for money and prefer to be led [16]. 
The notion of Father Leadership already researched within Kazakhstani small business framework is somewhat akin to the notion of authoritative leadership, where authoritative leader is the one who brings clarity to the organization [5]. It is this type of leader who sets a vision for employees to follow and makes sure that each employee knows clearly how his/her work fits into set vision and what needs to be done from his/her part to achieve a vision [5]. Authoritative leaders are supportive of their followers and employees as long as the vision is followed. They are thus supportive of innovation and creativity, so that the end result of authoritative leadership is generally is positive one. This type of leadership is mostly needed when new decisions or vision is required to organization. Here a parallel can be drawn between father leadership and authoritative leadership style of leadership, in a way that followers need support and instruction from a leader and the best result occurs if followers lack expertise in a particular area of responsibility. The common characteristics of authoritative leaders are that they model the desired actions required for working towards a vision, they have optimism and confidence that followers work towards the common vision rather than their personal agendas, they support their followers by providing them individualized consideration, they may have different ideas then their followers and respective ability to persuade followers of his/her ideas because of the high trust and commitment that followers demonstrate [7]. Nevertheless, authoritative leaders expect obedience and discipline from their followers. As such, employees in the organization become imprisoned with the processes and values deemed appropriate by the respective authoritative leader. The difference between the authoritative style and coercive style of leadership is the fatherly approach to the followers on the part of the former. Still, it could be stated that authoritative leadership style does not allow the full opening of innovative thoughts of employees, as those innovations are not implemented unless accepted by the leader.

A Democratic leader gives its employees a say in decision making process. This leadership style promotes collaboration, team leadership and communication [5]. The effectiveness of given leadership style depends on the abilities and knowledge of the employees and it is thus recommended to be used when employees are mature enough to participate in the decision making process. The overall impact of democratic leadership is a positive one [5]. Accordingly, due regard should be given to the circumstances surrounding the leader as a particular time, when choosing the leadership style that best suits the attainment of organizational goals. The common characteristics of democratic leaders is that they place high emphasis both on task and people [16]. This type of the leadership style presupposes long-term planning and establishment of clear objectives for the sake of effective performance and also heavy employee involvement. As such control is distributed between the leader and the employee. Communication under democratic leadership is open, two-way and genuine. This type of leadership activates innovative thoughts within organizations. Involved in decision-making process, employees approach their work from another prospective, more effort is applied to get the work done in an appropriate way. The consideration of professional innovative thoughts of employees form different levels of organization on the part of the leader contributes greatly to the success of the organization in the long-run.

Pacesetting leaders are the ones that set high standards and exemplify these standards by themselves [5]. The general result of pacesetting leadership is that it estimates responsibility and flexibility at work and is better suited when all the team players or employees are at more or less equal level of professionalism. It thus produces mostly negative results affecting employees' perception of their value and appreciation in a negative way. This type of leadership can also contribute to stagnation of the organization as affiliative leadership style, due to the fact that pacesetting leaders do not even try to develop to reach professional level expected by them, rather a pacesetting leader fires employees that do not suit his/her 
expectations. As the result of high employee turnover, the organization will not be able to foster shared cultural values comprehended by employees, as it takes time for newcomers to become immersed in the organizational processes, shared values, etc.

Coaching leadership style is based on the premise that each person has its own strengths and weaknesses and there are plenty of opportunities to develop them [5]. Coaching leaders provide their employees with a lot of feedback and instructions towards their goal achievement and thus this type of leadership style results in positive outcomes to the organizational climate and performance. In the long-run however the coaching leadership style can produce great results provided that employees/followers are committed to the organization and its goals. A leader with this type of the leadership style, as the name implies, can be compared to a coach in sports. It takes great effort and time for coach to distinguish people with particular capabilities to develop. Moreover, when people with corresponding capabilities are found, great effort and time are applied to develop those capabilities so that to achieve success. As is sports, coaching leaders in organizations are able to see the strong as well as weak sides of employees, so that to emphasize and work on strong one and minimize and impact of weak sides.

Transactional leadership style is as a style where a leader motivates the followers through rewards for services provided. The leader-follower relationship is based on the premise of exchanges, where followers receive extrinsic benefits for work performed that is accepted by the leader. If the leader deems the work performed to be of poor quality, the "carrot" turns to "stick" and the follower becomes punished for his/her inability to get the things done in a way sustainable for the leader. In transactional leadership style the emphasis is placed on the establishment of smooth operational performance with corresponding effectiveness and efficiency, where employees are required to do their work in accordance with the predefined rules and procedures. Transactional leaders focus on organizational process requirements and demand the implementation of those requirements from employees.

The following figure 1 as suggested by Bass [1] gives an insight to the core definition and implication of transactional leadership style: 
Figure 1. Leaders and Followers (L and F)

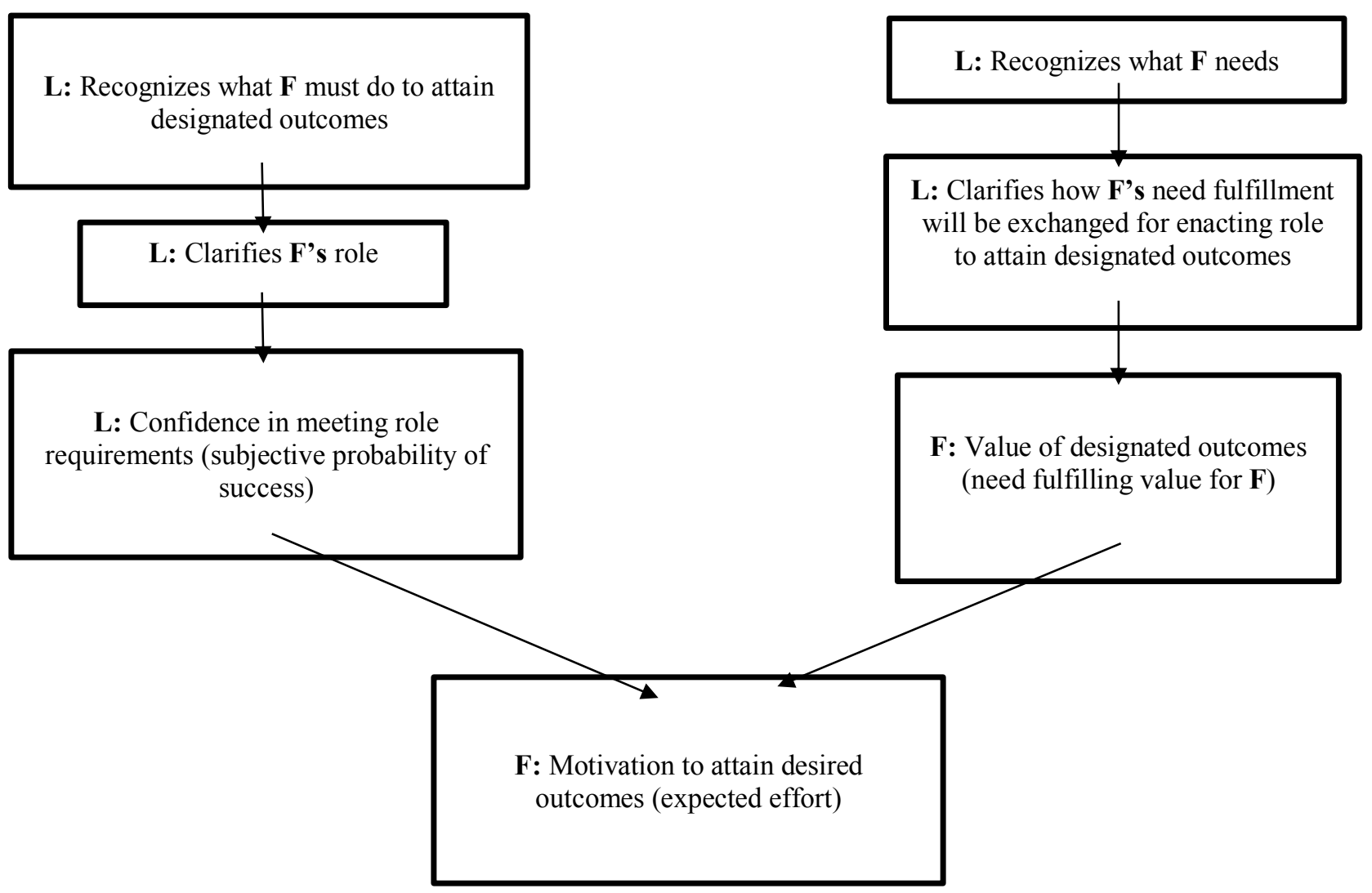

All of these factors comes to Motivation to attain desired outcomes (expected effort)

As it seen from Figure 1, transactional leader defines the needs of his/her followers and effectively uses those needs to define what followers should do to attain organizational goals. Moreover, from the above Figure 1, it can be implied that there is a link between the father leadership and transactional leadership style, as it is with authoritative leadership style. As in father leadership, transactional leaders explain followers what to do, define their priority tasks and make followers confident in the work they perform. Transactional leadership style involves leaders and followers in daily bureaucratic cores, where rules and procedures established within organizations are strictly followed and complied with. This leadership style can inhibit innovation within current circumstances. Nevertheless, transactional leadership style has a positive impact on daily business activities were things should be done in accordance with economic and legal requirements. Furthermore, like all other entities, companies should follow corresponding processes through defined procedures and ensure that those procedures are in place and are allowed. Moreover, to stay afloat, companies should comply with the legal and environmental requirements, where the rights and needs of all shareholders should be considered. Thus, this leadership style should be followed while maintaining normal business activities in the organization, but should be set aside while implementing innovative projects and considerable changes to meet the regulations of new economic situation in the marketplace.

Another important leadership style to look at is transformational leadership style. The notion of this style is to give a clear vison to the followers, so that they comprehend and adhere to the set vision. As opposed to transactional leadership style, the leaders with transformational style transcend the boundaries of giving orders and requiring their implementation through rewards or punishments, rather they try to comprehend the followers' requirements and 
manage to make followers accept the set direction. Transformational style entails innovation and change ant it questions the set procedures (Fenimore \& Niremberg, 2012). The leader asks the question on the applicability of the set processes and procedures. Here, the leader not just follows established rules and processes, but tries to see the logic behind these rules within the changing business environment and legal requirements. To the question "Why this report is done in this way?" transformational leader will not accept the following answer to the question "We have always done this way". In this situation a leader sees this is an opportunity to change the old way of doing things. Moreover, the leader tries to understand the followers' needs and aspirations.

Accordingly, leadership is an ability to influence people towards achievement of a certain vision and goal. There are different leadership styles that leaders use to influence their followers and these styles can be learned and practiced by leaders to produce great results for the attainment of organizational goals. Each of the styles mentioned above has its pro's and con's, and as a result affect performance of employees/followers either positively or negatively.

The research will include all leadership styles described in literature review and test the most appropriate one for Kazakhstan Financial Sector. Thus, hypothesis stands for the relationship between leadership styles and employees' performance, in particularly in what leadership style employees feel themselves more productive and ready to take a part in the company's development processes.

\section{Hypotheses}

\section{HYPOTHESES AND METHODOLOGY}

From the existing literature on leadership it can be assumed that impact of leadership on employee performance further leads to the effectiveness of the organization as a whole to maintain and develop its business activities. Therefore, the research questions of this research is:

1. How does leadership impact organizational effectiveness?

2. How does leadership influence corporate performance?

In this respect, the below hypothesis are subject for test:

H1: Leadership has an impact on employee performance

H1a: Transformational (TML), Democratic (DL) and Father Leadership (FL) styles have positive impact on employee performance;

H1b: Authoritative (AL), Coercive (CL) and Transactional Leadership (TCL) styles have negative impact on employee performance;

\section{Methodology}

The survey method was utilized for the collection of information for this research. Data was collected from different business organizations opening in Service. Trade and Manufacturing spheres. The survey consists of six parts: general information, leadership questions, knowledge management questions, corporate culture questions, questions related to employee performance and operational performance. The general information part consists of eight questions on personal information. Apart from the core questions (statements) related to the current research on leadership styles in the general information section respondents were asked to define the ownership of the organization they work for (foreign, local, or mixed), years of operation of the organization, approximate number of the employees in the organization, gender, age group, level of education and job position. Those statements are 
arranged on corresponding rating dimension based on a six point Likert scale ranging from "strongly disagree" or "strongly agree. The survey was distributed via social networks with the use of online survey as well as in hard copies from 150 employees. The survey was distributed in English as well as in Russian languages, so that to cover employees working in local organizations, who do not know English.

The sampling pool consists of employees from different spheres of business operation, who work in Almaty. The sampling pool can be considered respective of the whole Kazakhstan, due to the fact that considerable part of business activities whether large or small is concentrated in Almaty. Furthermore, Almaty is cosmopolitan city, where people from other regions come to do business, and where young people come from other parts of Kazakhstan to study and who decide to stay in Almaty.

\section{ANALYSIS AND FINDINGS}

Out of the different types of statistical tools the collected data was analyzed by using SPSS analytical system. For data analysis purpose the quantitative methods were used. Quantitative analysis is based on numerical representation of collected information. For this purpose, Pearson correlation coefficient were used. As per the definition from the site of University of West England Pearson correlation is "a measure of the strengths of the association between the two variables". In order to further proceed with the discussion of findings, it is worth initially to get a brief look at the values of Pearson correlation (Andale, 2014):

The results are arranged between -1 and +1 (Andale 2014).

High correlation: 0.5 to 1.0 or -0.5 to -1.0 (Andale, 2014).

Medium correlation: 0.1 to 0.3 or -0.1 to -0.3 (Andale, 2014).

Moving further with the discussion and analysis of findings, out of the total two hundred questions distributed, one hundred and fifty responses were returned and one hundred and nine were deemed appropriate for data analysis. Out of the total number of employees surveyed 26 per cent are male and 74 per cent are females. Furthermore, only 12 per cent of people surveyed have undergraduate degree, while 36 per cent have graduate and 52 per cent have master degrees.

From the information collected the corresponding correlation tables were prepared. Accordingly the previously outlined hypothesis can further be tested:

H1: Leadership has an impact on employee performance 
Table 1. Correlation matrix of leadership styles and employee performance

\begin{tabular}{|l|c|c|c|c|c|c|c|c|c|c|c|}
\hline & TML & FL & TCL & DL & AL & CL & CHRL & ESAT & EMOT & ECOM & ESTAY \\
\hline TML & 1 & & & & & & & & & & \\
\hline FL & $.530^{* *}$ & 1 & & & & & & & & & \\
\hline TCL & $.689^{* *}$ & $.421^{* *}$ & 1 & & & & & & & & \\
\hline DL & $.635^{* *}$ & $.471^{* *}$ & $.659^{* *}$ & 1 & & & & & & & \\
\hline AL & $.441^{* *}$ & .143 & $.572^{* *}$ & $.468^{* *}$ & 1 & & & & & & \\
\hline CL & $.191^{*}$ & .022 & $.378^{* *}$ & $.282^{* *}$ & $.734^{* *}$ & 1 & & & & & \\
\hline CHRL & $.527^{* *}$ & $.368^{* *}$ & $.503^{* *}$ & $.705^{* *}$ & $.502^{* *}$ & $.390^{* *}$ & 1 & & & & \\
\hline ESAT & $.593^{* *}$ & $.444^{* *}$ & $.491^{* *}$ & $.458^{* *}$ & .173 & -.061 & $.438^{* *}$ & 1 & & & \\
\hline EMOT & $.647^{* *}$ & $.474^{* *}$ & $.521^{* *}$ & $.470^{* *}$ & $.194^{* *}$ & -.079 & $.447^{* *}$ & $.848^{* *}$ & 1 & & \\
\hline ECOM & $.621^{* *}$ & $.403^{* *}$ & $.470^{* *}$ & $.466^{* *}$ & $.160^{* *}$ & -.046 & $.399^{* *}$ & $.865^{* *}$ & $.868^{* *}$ & 1 & \\
\hline ESTAY & $.628^{* *}$ & $.447^{* *}$ & $.502^{* *}$ & $.490^{* *}$ & $.229^{* *}$ & .039 & $.503^{* *}$ & $.859^{* *}$ & $.850^{* *}$ & $.882^{* *}$ & \\
\hline
\end{tabular}

Variables are Transformational (TML), Democratic (DL), Father Leadership (FL) Authoritative (AL) Coercive (CL) and Transactional Leadership (TCL), employees' satisfaction (ESAT), employees' motivation (EMOT), employees' commitment (ECOM) and ESTAY

As it is seen from Table 1 , there is a link between leadership style a leader utilizes and employee performance., as the correlation values $(r)$ range between -1 and $+1(p<0.001)$. As in the case with operational performance, some leadership styles have positive correlation with employee performance, while some have negative correlation. It was already tested that strict, harsh leadership styles have mostly negative correlation with operational performance, while more democratic leadership styles have positive correlation with operational performance. Thus, the following hypothesis is subject for test to see if the same holds true for employee performance, as it is the case with operational performance.

Initially, the hypothesis on positive correlation with employee performance will be tested.

H1a: Transformational, Democratic and Father Leadership styles have positive impact on employee performance:

As it is shown in Table 2, Leadership styles and employee performance correlation is analyzed in four dimensions: employees' satisfaction, employees' motivation, employees' commitment and ESTAY dimension. As per the Table 4, the Transformational (TML) leadership style is positively correlated with the employee performance. The employees' satisfaction dimension has correlation of $r=.593(p<0.001)$, correlation on employee's commitment is $r=.621$ $(\mathrm{p}<0.001)$, the longer period of time employees want to stay in the company dimension has correlation value of $r=.628(p<0.001)$ and finally employees' motivation has $r=.647(p<0.001)$. the highest correlation is between Transformational (TML) leadership style and employee's motivation, as transformational leaders transcend the borders of being a boss, but they try to understand the core implications of the issue at hand, possibilities to get opportunities internally and externally and make employees not only follow endeavors of the leader, but also 
provide their solutions and ideas that promote performance of an organization. The analysis implies that Transformational leaders lead their followers through establishing good, healthy working environment, where employees become satisfied, motivated and committed to work for the sake of the organization for a long time in an efficient and effective way.

The Democratic (DL) leadership style has also positive correlation with employee performance. The correlation for employees' satisfaction dimension is $r=.458(p<0.001)$, for employees' commitment is $\mathrm{r}=.466(\mathrm{p}<0.001)$, employees' motivation is $\mathrm{r}=.470(\mathrm{p}<0.001)$ and the longest period of time employees want to stay at company is $r=.490(p<0.001)$. As in Transformational leadership style, Democratic leadership style allows employees to feel that they can be heard and that they can provide their inputs, so that to add value to the organizational performance, thus is the reason for high correlation between Democratic (DL) leadership style and employee performance.

The relatively high correlation of Democratic leadership and Transformational leadership styles with employee performance show that surveyed employees feel that if a leader utilizes those leadership styles, then behavior and approach to employees present in those styles make employees more motivated, satisfied and more willing to be committed and stay in the company for a long time.

As for the Father (FL) Leadership style, there is also high positive correlation of this type of leadership and employee performance. The correlation for employees' commitment is $r=.403$ $(\mathrm{P}<0.001)$, for employee satisfaction is $\mathrm{r}=.444(\mathrm{p}<0.001)$, for longer period of time employees want to stay in the company dimension it is $r=.447(\mathrm{p}<0.001)$ and for employees' motivation it is $r=.474(p<0.001)$. Here, it can be also implied that employees want to feel themselves safe and in a warm and friendly environment to be satisfied, motivated, committed and stay for a longer period with organizations. Father Leadership cares about employees and as it is seen from the analysis of the responses employees want to experience a family like environment, where they can express their ideas and aspirations and where a leader provides advice and support.

To sum up, following the above analysis of the results there is high positive correlation between Transformational, Democratic and Father Leadership styles and employee performance, thus the Hypothesis H1a is confirmed.

Initially, the hypothesis on positive correlation with employee performance was tested. Further the hypothesis on negative correlation is to be tested.

H1b: Authoritative, Coercive and Transactional leadership styles have negative impact on employee performance:

Following the above hypothesis, it can be seen from Table 2 that the Transactional (TCL) leadership style is positively correlated with employee performance. The employees' commitment has correlation value of $r=.470(p<0.001)$, employees' satisfaction has correlation value of $\mathrm{r}=.491(\mathrm{p}<0.001)$, the longer period of time employees want to stay with the organization dimension has correlation value of $r=.502(\mathrm{p}<0.001)$ and the highest correlation value for employees' motivation, which is $r=.521(\mathrm{p}<0.001)$. As in the case with operational performance, the Transactional (TCL) leadership style is positively correlated with employee performance. This fact holds true as per the corresponding analysis and the reason for this might be the fact that employees know what they are required to do and how, as leaders utilizing transactional leadership style ensure the smooth operational day-to-day activities in compliance with established practices and procedures. Furthermore, the positive correlation of 
Transactional leadership and employee performance implies that in normal business activities employees feel more comfortable when they are supplied with corresponding instructions, manuals and when they are supervised and supported by their leaders.

Authoritative (AL) leadership style is still positively correlated with employees' motivation, but the correlation is low. For employees' commitment dimension correlation value is $r=.160$ $(p<0.001)$, for employee satisfaction correlation value is $r=.173(p<0.001)$, for employees' motivation correlation value is $r=.194(p<0.001)$ and finally for the longer period of time employees want to stay in the organization dimension it is $r=.229(p<0.001)$. Surprisingly, though the correlation between authoritative leadership style and employee performance is low, still it is positive with the relatively higher correlation for ESTAY dimension. This might be linked to the fact that Authoritative leadership style is somewhat alike Father Leadership style, where a leader not only enforces rules and procedures established by him/her and requires strict compliance, but who approach employees in a fatherly manner, in some cases to give advice and support.

Concerning the Coercive leadership style it can be seen that it is negatively correlated with employee performance. For employees' commitment the correlation coefficient is $\mathrm{r}=-.046$ $(p<0.001)$, for employees' satisfaction correlation coefficient is $r=-.061 \quad(p<0.001)$, for employees' motivation correlation coefficient is $\mathrm{r}=-.079(\mathrm{p}<0.001)$, and for ESTAY dimension, surprisingly the correlation coefficient is $r=.039$ ( $p<0.001)$, which implies that there is positive correlation, though low. There is no surprise that generally Coercive leadership style is negatively correlated with employee performance, as leaders, who use Coercive leadership style for managing and leading employees not only prohibit employees to propose and introduce new projects and ideas, but also use threats and force, in order to make employees follow not only rules and requirements established by the leader, even if those rules are in contradiction with generally accepted procedures and legal requirements.

To sum up, as it was defined Transactional and Authoritative leadership styles are positively correlated with employee performance, thus the hypothesis H1b is not confirmed for these leadership styles. Nevertheless, Coercive leadership style is generally negatively correlated, thus it can be stated that hypothesis H1b for this type of leadership style is negatively correlated and is confirmed.

\section{CONCLUSIONS}

This research is confirmed by the positive correlation of Transformational, Democratic and Father Leadership styles with operational, employee performance. This fact also supports the notion that with the move from directive centralized business coordination present during USSR, to free economic relations, business leaders and employees in the organizations have changed, might not be entirely, but somewhat the attitudes and behaviors towards leading, executing business activities and towards each other. Furthermore, what is very interesting is that according to findings relatively new leadership style as Transformational style has mostly the highest positive correlations with operational and employee performance. This can be linked to the fact that most of the respondents were representatives of young generation, about 8 per cent and most of them work for foreign companies, about 41 per cent. Moreover, as the findings suggest, Kazakhstani employees also favor Father Leadership style. As the previous study suggests, employees in Kazakhstan prefer to be supported and consider work environment and colleagues as part of a family. Kazakhstani employees consider the work environment not just as pure business place, but also a place, where they can create and sustain good family-like relationships with colleagues. For instance, if in western countries 
employees easily report on their colleagues for wrong actions on their part to corresponding controls department, then for employees in Kazakhstan this might not be so easy, though reporting on colleagues that perform illegal acts is right thing to do, in order to protect the reputation of the organization and to work among reputable colleagues. Again this is the implication that though Farther Leadership has mostly positive sides, it should be correctly employed by the leader, in order to avoid the situations, where employees perform wrong acts or stay calm in order to protect their colleagues. Furthermore, findings also show that there is positive, though low correlation of Authoritative leadership style with operational and employee performance. This can be attributed to the two major elements. The first one is related to the attitudes of employees to the behavior and values of an Authoritative leader as a soft remnant of the USSR time, where employees were directed and were told what to do and where employees consciously were convinced that this is the right way to lead people to attain organizational goals. Some respondents were representatives of the generation that witnessed the time of USSR rule, about 18 per cent, thus is the positive correlation of Authoritative leadership with employee and operational performance. The second reason might be attributed to the fact that Kazakhstan is a young country, where along with worldwide recognition as a sovereign country and good reputation among other countries, Kazakhstan also established good business activities both on domestic as well as on an international level. Nevertheless a lot of things need to be done in the business sphere in order to firmly admit that our business can easily compete with advanced countries. As it was defined in the literature review section, Authoritative leadership style is the style that best suits organizations at the time of defining new direction and vision and this is one of the key factors that current organizations require. Furthermore, as the study shows that while there is low, but still positive correlation of Authoritative and Transactional leadership styles on operational and employee performance, there is high negativity towards Coercive leadership style. As the study suggests there is rejection of any sign of Coercive leadership style that inhibits not only innovative thoughts among employees, but also restrains employees from performance of dayto-day work required for maintaining normal business activities. To conclude, it is important to state that while choosing the appropriate leadership style to utilize in Kazakhstan within business framework, one can take into consideration outcomes of the analysis outlined in this research along with other factors.

\section{References}

Bass (1985), Leadership and performance beyond expectations, p.12.

Chmielewska-Muciek D., Sitko-Lutek A. (2013). Organizational culture conditions of knowledge management. International Conference 2013.

Fenimore C. J., Nirenberg J. (2012). Leadership effectiveness. Encyclopedia of leadership, 1-3.

Goleman D. (2014). Daniel Goleman: How leaders Can Overcome Obstacles for Change.

Goleman D. (2000). Leadership that gets results. Harvard business review, 83-87.

Isaacs, R. (2010). "Papa" - Nursultan Nazarbayev and discourse of charismatic leadership and nation-building in Post-Soviet Kazakhstan. Studies in Ethnicity and Nationalism: Vol.10, No.3, 2010.

Kirkpatrick, S.A. (2011). Visionary leadership theory. Sage publications.

Koenig M.E.D. (2012). What is KM? Knowledge management explained. KM World.

Mills D.Q. (2005). Leadership: How to lead. How to live. The importance of leadership, 10-12.

Murray A. (2013) Leadership styles.

Ogbonna E., Harris L.C (2000). Leadership style, organizational culture and performance: empirical evidence from UK companies Int. J of Human Resource Management 11:4 August 2000, 766-788.

Patrick Kim Cheng Low (2007). "Father leadership and small business management: The Kazakh perspective", Journal of Management Development, Vol.26 Iss:8, pp.723-736. 
Tharp B.M. (2009). Four organizational culture types.

Tharp B.M. (2009), Defining "Culture" and "Organizational culture": From Anthropology to the Office.

Tolymbek, A. (2006). Political leadership style in Kazakhstan.

Warrick, D. (1981). Leadership styles and their consequences. Journal of experiential learning and simulation, 3-4: 155-172.

Winston B. \& Patterson K. (2006). An integrative definition of leadership. (Electronic version). International journal of leadership studies, 6 . 